\title{
PGPR Potentially Improve Growth of Tomato Plants in Salt-Stressed Environment
}

\author{
Mariam Zameer ${ }^{1}$, Hina Zahid ${ }^{1}$, Bushra Tabassum ${ }^{2}$, Qurban Ali ${ }^{*}$, Idrees Ahmad Nasir ${ }^{2}$, \\ Muhammad Saleem ${ }^{3}$, Shahid Javed Butt ${ }^{4}$
}

${ }^{1}$ College of Earth and Environmental Sciences, University of the Punjab, Lahore, Pakistan.

${ }^{2}$ Centre of Excellence in Molecular Biology, University of the Punjab, Lahore, Pakistan.

${ }^{3}$ Molecular Genetics Research Laboratory, Department of Botany, University of the Punjab Lahore, Pakistan

${ }^{4}$ Department of Biotechnology, School of Sciences, University of Management and Technology, Sub-Campus Sialkot, Pakistan

\section{A R T I C LEIN F O}

Article history:

Received ?? ???????

Accepted ?? ???? ????

Available online, ISSN: 2148-127X

Keywords:

Rhizobacteria

PGPR

Bacillus megaterium

Gene expression

Glutathione reductase

Metallothionein

${ }^{*}$ Corresponding Author:

E-mail: saim1692@gmail.com \begin{abstract}
A B S T R A C T
Özet Plant growth promoting rhizobacteria are colonized bacterial species that has the capability to improve plant growth by certain direct and indirect means. Environmental factors including both biotic and abiotic stresses are among the major constraints to crop production. In the current study, the effectiveness of microbial inoculation (Bacillus megaterium) for enhancing growth of tomato plants under salt stress conditions has been investigated. Significant improvement in shoot length, root length, leaf surface area, number of leaves, total weight of the shoot and root was observed in tomato plants inoculated with zm7 strain post 15 and 30 days of its application. Zm3, Zm4 and Zm6 strains improved the morphological parameters as compared to the control. Chlorophyll content a, chlorophyll content $\mathrm{b}$, anthocyanin and carotenoid content was increased in tomato plants subjected to $\mathrm{Zm} 7, \mathrm{Zm} 6$ and $\mathrm{Zm} 4$ strains. Stress responsive genes; metallothionein and glutothion gene were found highly expressed in $\mathrm{Zm} 7$ treated tomato plants as compared to control, untreated plants. Significant correlation of anthocyanin was reported for carotenoids, chlorophyll-b, shoot weight and total weight of seedling while carotenoids was significantly correlated with leaf surface area, root length, chlorophyll-b and anthocyanin. Overall, $\mathrm{Zm} 7$ strain proved best for improvement in salt sressed plant's morphological parameters and biochemical parameters as compared to control, untreated plants.
\end{abstract}

\section{Introduction}

For over 3000 years, salinity has been a major threat to agriculture in various parts of the world. As the world population increases, more food is required along with utilization of more agricultural land and more production per unit area. It is estimated that approximately $20 \%$ of all irrigated lands are salt-affected (Pitman and Lauchli 2002). However, the total global area of salt-affected soils has recently been estimated to be approximately 830 million hectares (Martinez-Beltran and Manzur 2005). Salinity is one of those factors which deteriorates the agricultural land and vitally affects the economic development and also the nutritional standards (Ezlit et al., 2010). Plant scientists are putting their efforts in developing salt-tolerant crops by genetic approaches (Munns, 2005; Yamaguchi and Blumwald, 2005; Cuartero et al., 2006; Munns et al., 2006). But as the complex interplay of certain biochemical, molecular and physiological mechanisms involved in salt stress has not been fully understood, development of salt tolerant crops is overdue.

Stress, in general, affect the growth of the plant by various means including hormonal imbalance, susceptibility towards disease, nutritional imbalance etc. (Nadeem et al., 2014). In urge of improvement in salinity tolerance worldwide, use of biological agents has been reported from many years (Glick et al., 2007; Yang et al., 2008; Zahir et al., 2008; Adesemoye et al., 2009; Bhattacharyya and Jha, 2012). These microbes termed as plant growth promoting rhizobacteria (PGPR), regulate hormonal and nutritional balance, solubilize nutrients, produce plant growth regulators and induce resistance in plants (Korneli et al., 2012; Nadeem et al., 2014). Plant growth promoting rhizobacteria is a varied group of colonizing bacteria, which When grown with plants cause growth stimulation and direct indirect promotions (Vessey, 2003; Banchio et al., 2008). PGPR are considered as the best remediation for treating saline soil (Figueiredo et al., 2010) by a number of direct and indirect mechanisms (Glick et al., 2007; Nadeem et al., 2010b). PGPR helps in synthesis of particular compounds, uptake of nutrients and act as an antidote for plants (Szczech and Dysko, 2004; Zameer et al., 2015a). PGPR present in rhizospehere soil; area surrounding plant root undergoing intense bio-chemical activities by root 
exudates and microorganisms feeding on compounds, promotes plant growth, yield, solubilization of nutrients as phosphorous, nitrogen, potassium etc via inoculation (phytoharmones) with PGPR (Hayat et al., 2010). They act as biocontrol agents via squirting siderophores, capability to fuse anti-fungal metabolites and antagonism for specific niches on root (Singh et al., 2013). Plants give responses to salt stress by means of cellular, tissue and whole plant level. When chemical activity of water decreases and turgor loss occurs it indicates that hyperosmotic shock (Nutritional imbalance, hypoxia and hyper osmotic stress) is stirring (Borsani et al., 2003; Goupil et al., 2009). Salt tolerance is a dense trait in which long catalogues of genes responsive to salt stress are involved. Genes responsible for salt tolerance can be identified by gene expressions regulated by salt stress, the genes that gather organic compounds can be considered as the "salt determinants" (Borsani et al., 2003). In the present study, effect of four rhizobacterial strains on morphological and biochemical parameters of the tomato plants grown in salt-stressed environment were studied. The mRNA expression of two stress responsive genes; GR (glutathione reductase) and MT (metallothionein) was revealed in this study.

\section{Materials and Methods}

\section{PGPR \& Plant Material}

Four strains of Bacillus megaterium (Zm3, Zm4, Zm6, $\mathrm{Zm} 7)$ were kindly obtained from Institute of Agriculture Sciences (IAGS), Punjab University, Lahore sourced by maize rhizosphere. The strains were maintained onto LB Agar media. Tomato (Lycopersicon esculentum) variety Rio brand were grown in greenhouse under controlled conditions. Three weeks old plantlets were subjected to salt stress treatment.

\section{Bacterial Inoculums}

Each bacterial strain; Zm3, Zm4, Zm6 and Zm7 was grown overnight at $37^{\circ} \mathrm{C}$ in $\mathrm{LB}$ broth media. Bacterial culture was centrifuged at $4 \mathrm{~K}$ RPM for $15 \mathrm{~min}$ and cells were collected. For inoculums, harvested cells were prepared in a saline concentration adjusted to 1000 cells per $\mathrm{ml}$ through the use of UV light with $600 \mathrm{~nm}$ wavelength (OD600).

\section{Greenhouse Experiment}

Plastic pots of 10 inch diameter were filled with sterilized silty loam and tomato seedlings were transferred in these pots. For each individual bacterial treatment, ten replica pots were installed with three replicas in each pot. In total, 110 pots (each having 3 replicas) were included in the study. For each bacterial strain, $100 \mathrm{ml}$ of bacterial inoculum was applied to tomato plantlets individually. After fifteen days interval, plants were provided with the salt solution of $100 \mathrm{mM}$ and $200 \mathrm{mM}$ concentration. Randomly five leaf samples were taken from tomato plantlet after every 15 days against each treatment of PGPR and data was recorded.

\section{Growth Parameters}

Four different morphological parameters; plant height, leaf surface area, root length, biomass of root and shoot length were considered to analyze the effect of PGPR on tomato plants in saline environment. However chlorophyll content, carotenoids and anthocyanin level were quantified by calorimetric method. For this, few leaves were taken and meshed with $2 \mathrm{ml}$ of acetone until the green colored pigment extracted. Further, the pigment was filtered and $0.05 \mathrm{ml}$ of this extract was added with $0.95 \mathrm{ml}$ of $80 \%$ buffered acetone for spectrophotometric quantification by using the following formulas.

Ant $=0.08173$ A537-0.00697 A647-0.002228 A663
Cha $=0.01373$ A663-0.000897 A537-0.003046 A647
Chb $=0.02405$ A647-0.004305 A537-0.005507 A663
Car $=$ A470-(17.1 x Cha + Chb) $-9.479 \times$ Ant $/ 119.26$

Where;

Ant : Anthocyanin $(\mu \mathrm{mol} \mathrm{ml-1)}$

Cha : Chlorophyll a ( $\mu$ mol ml-1)

Chb : Chlorophyll b ( (mol ml-1)

Car : $\underline{\text { Caretenoids }}(\mu \mathrm{mol} \mathrm{ml-1)}$

\section{RNA Isolation and RT-PCR Assay}

One replica of tomato plants was treated with $\mathrm{zm} 7$ strain alone. 15 days post treatment; the plants were analyzed for the expression of stress related genes. Total cellular RNA was isolated from tomato leaves collected randomly at 15 days and 30 days interval against each individual PGPR treatment. TRIzol reagent (Invitrogen) was used to isolate RNA as per manual. Complementary DNAs were synthesized using cDNA synthesis kit (cat \# k0612; Thermoscientific) while PCR was performed using gene specific primers (Table 1) in a total $20 \mu \mathrm{l}$ reaction mixture containing $10 \mathrm{X}$ PCR buffer, $1.5 \mathrm{mM}$ $\mathrm{MgCl}_{2}, 1 \mathrm{mM}$ dNTPs, 10pmoles of both forward and reverse primer, 2 units of Taq DNA polymerase, 100ng of cDNA as template and water to make up volume. Cycling profile was $94^{\circ} \mathrm{C}$ for 5 minutes followed by 35 cycles of denaturation at $94^{\circ} \mathrm{C}$ for $30 \mathrm{sec}$, annealing at $55-58^{\circ} \mathrm{C}$ for $30 \mathrm{sec}$ and extension at $68-72^{\circ} \mathrm{C}$ for $30 \mathrm{sec}$ followed by final extension at $72^{\circ} \mathrm{C}$ for 10 minutes.

\section{Performance of Tomato Plantlets under Salt Stress}

The performance of tomato plantlets under saline stress conditions was measured by the given formula. Morphological parameters of the plant were taken.

Where;

$$
=\frac{\mathrm{PTC}-\mathrm{PS} \times 100}{\mathrm{PTC}}
$$

PTC : Performance in treated conditions

PS : Performance in salinity

\section{Statistical Analysis}

The data were recorded for morphological traits including root length, shoot length, number of leaves, leaf surface area and biochemical traits; carotenoids, anthocyanin, chlorophyll-a and chlorophyll-b. The data 
was subjected for analysis of variation by using Steel et al. (1997) technique.

Table 1 Sequence of primers used for specific amplification of stress responsive genes.

\begin{tabular}{l|ll}
\hline Title & Primer ID & Sequence \\
\hline \multirow{2}{*}{ Metallo -thionein primers } & MT Fw: & 5'GCTGTGGATCTAGCTGCAAGTGCG,3' \\
& MT Rev: & 5'-AAGGGTTGCACTTGCAGTCAGATCC,3' \\
\hline \multirow{2}{*}{ Glutathion reductase primers } & GR Fw: & 5'-TCCCATCGGCTCTGAAGTTAGTGGG,3' \\
& GR Rev: & 5'-TCTTTGCATCCTCCAGTTCTGGCCC,3' $^{\prime}$ \\
\hline \multirow{2}{*}{ House Keeping gene primers } & Actin Fw: & 5'-GGGATGGAGAAGTTTGGTGGTGG,3' \\
& Actin Rev: & 5'CTTCGACCAAGGGATGGTGTAGC,3' $^{\prime}$ \\
\hline
\end{tabular}

\section{Results}

Pgprs Improve Morphological Traits in Subjected Tomato Plants

Visual observations of experimental plants were made regarding overall growth of the plants under salt stress concentrations $100 \mathrm{mM}$ and $200 \mathrm{mM}$. Morphological parameters; shoot length, leaf surface area, no. of leaves and root length were compared in tomato plants treated with bacterial strains $\mathrm{zm} 3, \mathrm{zm} 4, \mathrm{zm} 6$ and $\mathrm{zm} 7$ fifteen days post treatment. A biplot (Figure 1) depicted that plants treated with $\mathrm{zm} 7$ strain exhibited significant increase in leaf surface area and no. of leaves; $\mathrm{zm} 3$ treated plants showed increase in leaf surface area and root length while zm6 treated tomato plants exhibited shoot length increase and in no. of leaves. Control, non-treated plants and zm4 treated plants have no significant improvement in morphological parameters. Conclusively, plants treated with $\mathrm{zm} 7, \mathrm{zm} 3$ and $\mathrm{zm} 6$ showed improvement in investigated morphological parameters after fifteen days post treatment as compared to control, non-treated plants. Figure 2 showed the status of morphological parameters 30 days post PGPR-treatment. Significant improvement in shoot length, leaf surface area and root length was observed in plants treated with $\mathrm{zm} 6$ and $\mathrm{zm} 7$ bacterial isolates. Zm4 treated plants also exhibited increase in number of leaves as compared to control, non-treated plants. Overall, growth of the PGPR-treated plants was significantly improved after application of PGPR when compared with control, non-treated plants at 15 days post PGPR application as clear from Figure 1 and Figure 2.

Conclusively, zm7 strain treated tomato plants showed significant improvement in shoot length, root length and total weight of the subjected plants 15 days post their application. Although zm6 was able to improve total weight of the subjected plant but was unable to improve other investigated parameters. Similarly, zm3 and zm4 didn't exhibited any improvement in the overall growth of shoot, root and in total weight of the plant when assessed 15 days post PGPR inoculation (Figure 3). The same findings were met when any improvement of morphological traits was studies in tomato plants subjected to PGPR application 30 days post their application (Figure 4). zm7 strain enhanced the overall growth of the tomato plants grown in saline stress. However, control plants didn't show any significant improvement among all studied parameters (Figure $3 \&$ 4). Conclusively, replicas of ZM7 and ZM4 at both $100 \mathrm{mM}$ and $200 \mathrm{mM}$ showed significant improvement in

morphological characters of the treated plants as compared to ZM6 and ZM3. Thus, best response for morphological trait improvement was given by $\mathrm{zm} 7$ strain. Significant improvement was at $100 \mathrm{mM}$ salt concentration as compared to $200 \mathrm{mM}$.

PGPR Improve Biochemical Content of Subjected Plants Under Salt Stressed Conditions

Under salt stress condition (both at $100 \mathrm{mM}$ and at $200 \mathrm{mM}$ ), the content of chlorophyll a and level of anthocyanin was enhanced by zm7 strain when applied onto tomato plants in comparison with control, untreated plants. The data was recorded 15 days post PGPR application. It was found that carotenoid level and content of chlorophyll a, b was increased in $\mathrm{zm} 4$ treated plants while zm6 treated plants showed enhanced level of carotenoids and chlorophyll a (Figure 5). However, control, untreated plants didn't exhibited any increase in above said biochemical parameters 15 days post treatment. Similar findings were met when chlorophyll a, b, carotenoid, anthocyanin contents were measured in PGPR-treated tomato plants post 30 days (Figure 6). Zm7 significantly enhanced levels of chlorophyll a and carotenoid; zm4 increased anthocyanin content while zm6 significantly improved the amount of anthocyanin as compared to control, untreated plants where no significant improvement was found of these biochemical parameters as depicted in Figure 6.

Zm7 Trigger Accumulation of Stress-Related Transcripts

In zm7 treated tomato plants, two stress related genes; metallothionein and glutothion gene were found expressed at various time periods post treatment with $\mathrm{zm} 7$ as PGPR (Figure 7). In executed experiment, Bacillus megaterium strains induced the expression of the stress related protein gene. Exposure of tomato plants to Bacillus megaterium strain led to dramatic changes in the abundance of stress-related transcripts, MT2 and GR1 (Figure 7). The highest response of the MT2-like gene was at 24 hpi. The highest levels of GR1-like protein transcript accumulation were detected at 36 hpi. The Bacillus megaterium treatment, in general, induced greater transcript accumulation in tomato plants. In control plants, the molecular response of MT2- and GR1like genes led to lower levels of transcript accumulation compared to the bacterial treated plants. Beta actin was used as internal control. 


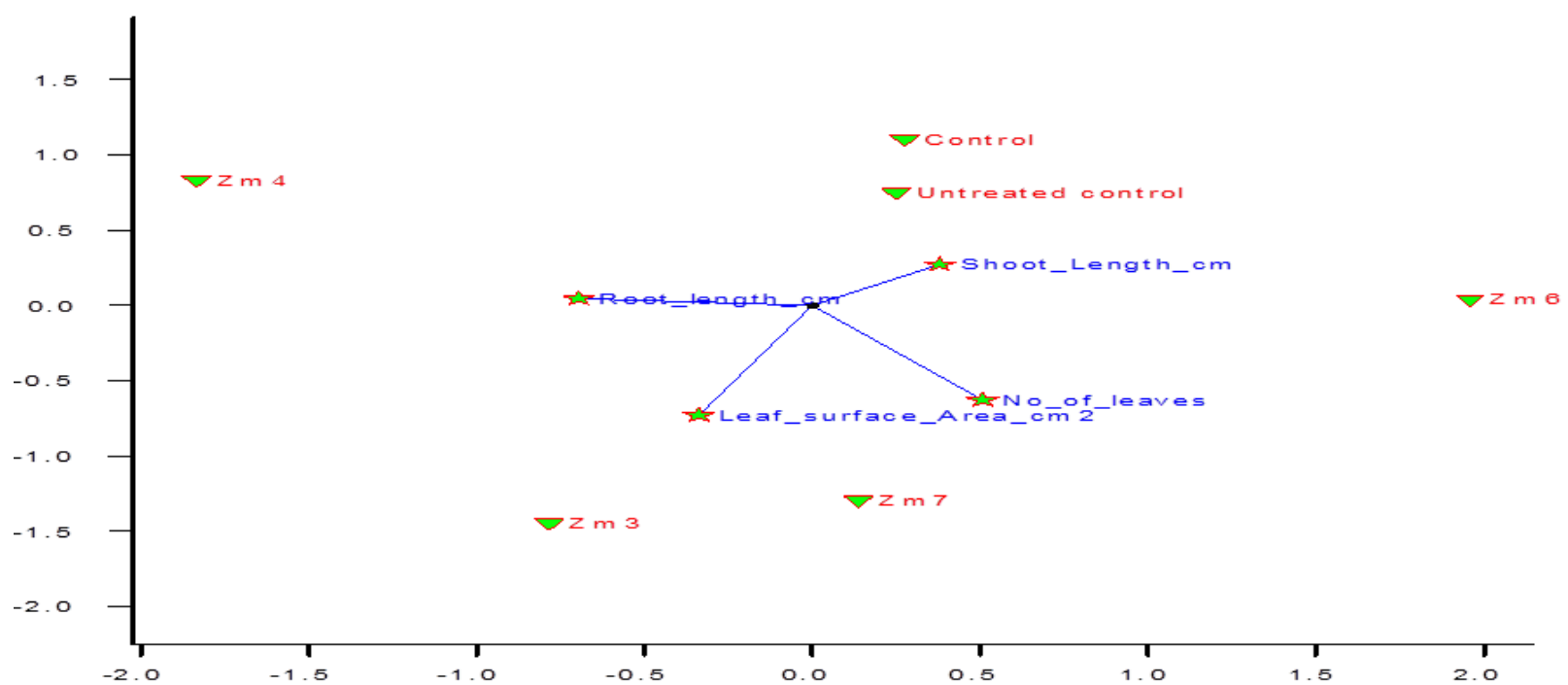

Figure 1 A biplot depicting correlation between PGPR-treated tomato plants and control, non-treated plants regarding four morphological parameters 15 days post PGPR treatment.

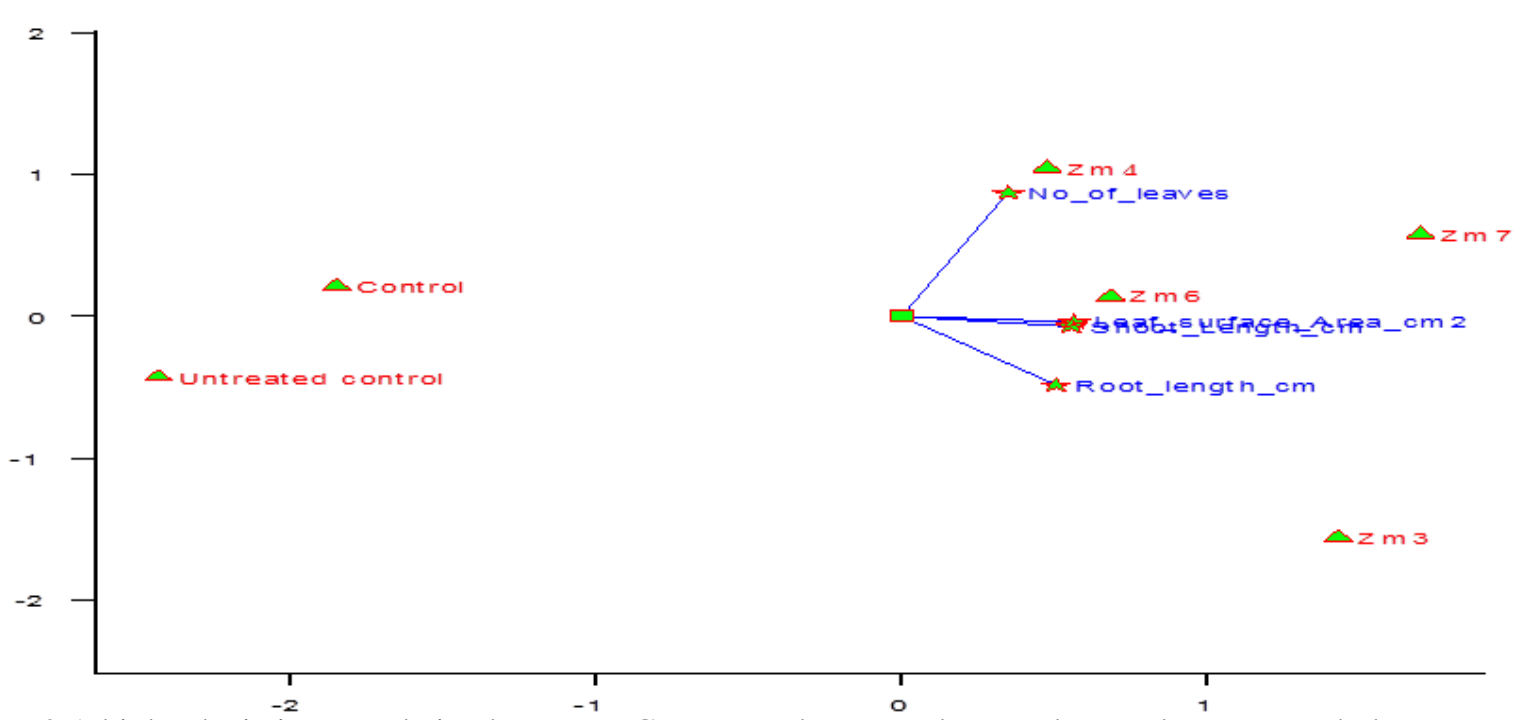

Figure 2 A biplot depicting correlation between PGPR-treated tomato plants and control, non-treated plants regarding four morphological parameters 30 days post PGPR treatment.

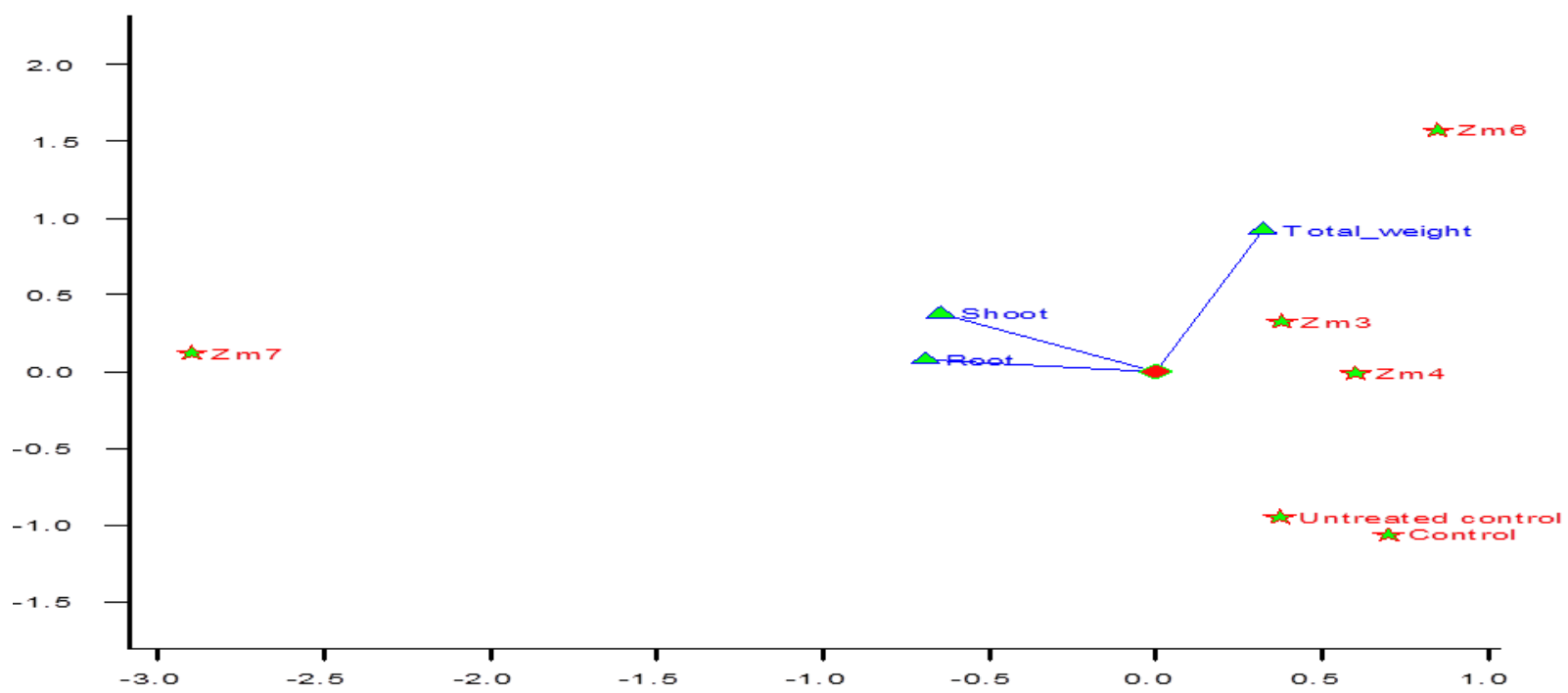

Figure 3 A biplot depicting overall performance of tomato plants grown in saline stress conditions for all weight parameters 15 days post application of PGPR. 


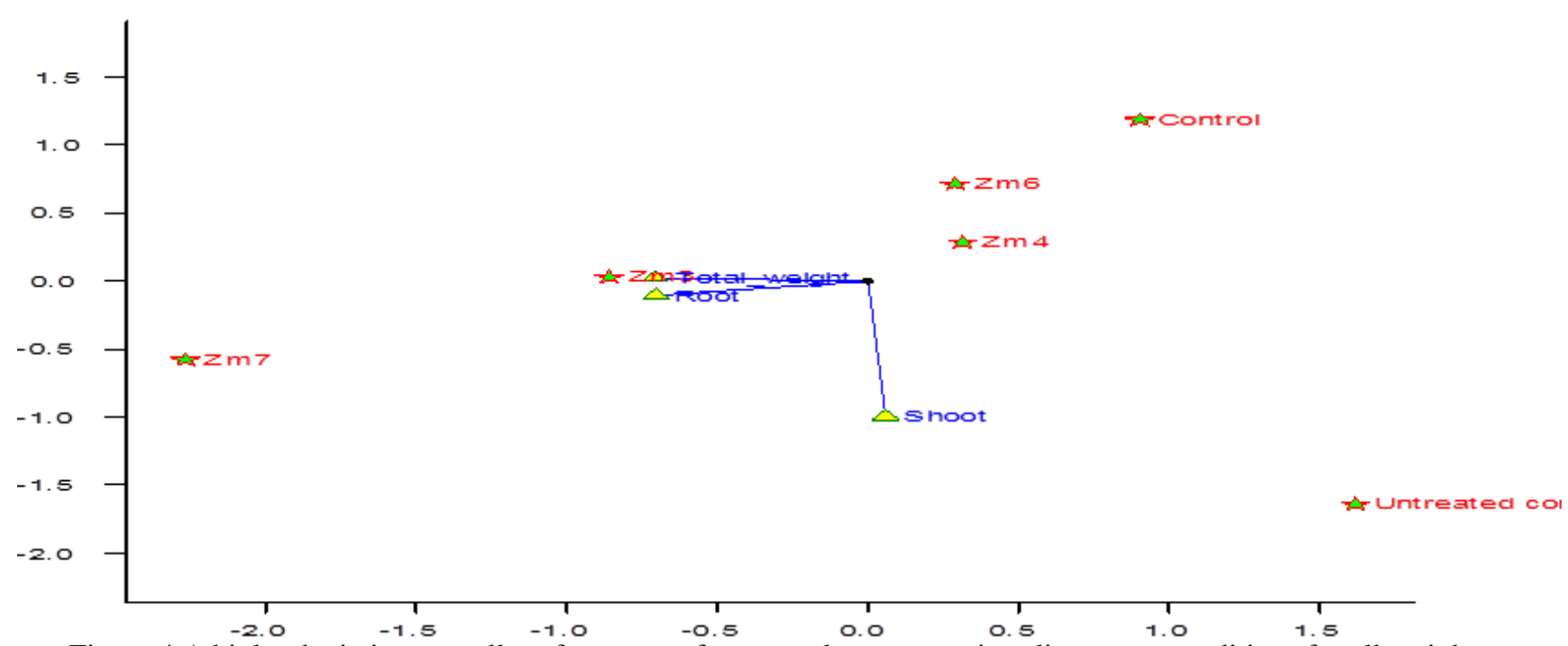

Figure 4 A biplot depicting overall performance of tomato plants grown in saline stress conditions for all weight parameters 30 days post application of PGPR.

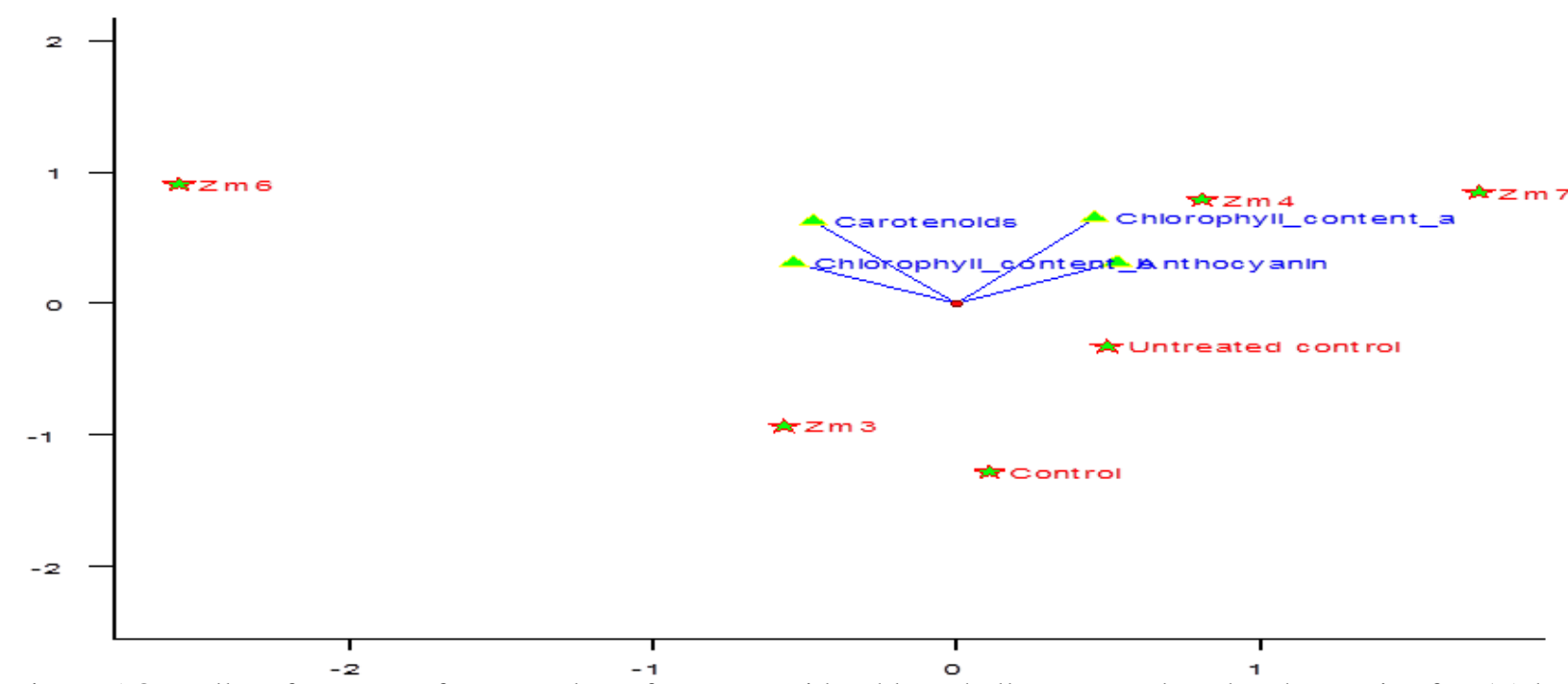

Figure 5 Overall performance of tomato plants for carotenoids, chlorophyll content a, b and anthocyanin after 15 days of PGPR applications.

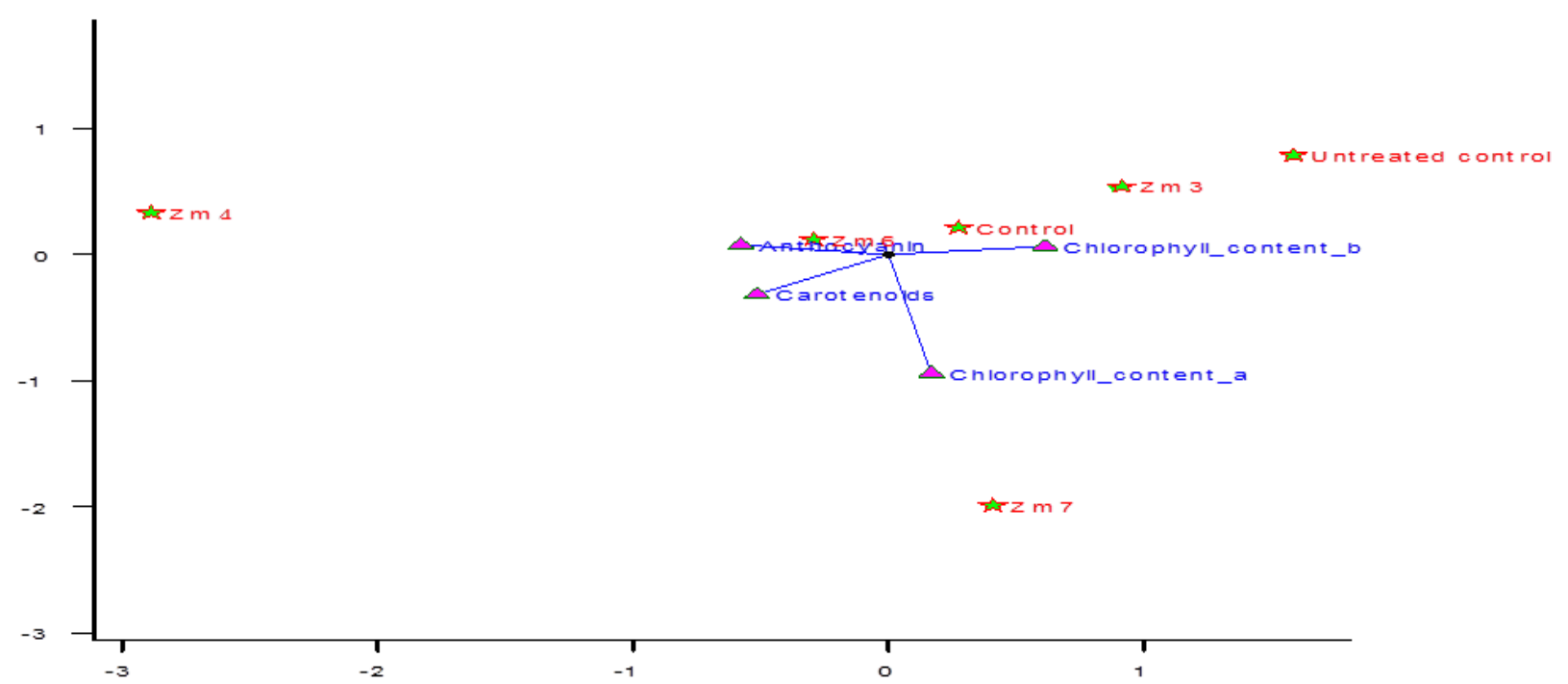

Figure 6 Overall performance of tomato plants for carotenoids, chlorophyll content a, $\mathrm{b}$ and anthocyanin, 30days post PGPR application. 
Significant correlation of anthocyanin was reported for carotenoids, chlorophyll-b, shoot weight and total weight of seedling while carotenoids was significantly correlated with leaf surface area, root length, chlorophyll$\mathrm{b}$ and anthocyanin as depicted as table 1. Chlorophyll-a was significantly correlated with leaf surface area, total weight of seedlings, root weight and shoot length while chlorophyll-b was significantly correlated with shoot weight, total weight of the seedlings and root weight. Leaf surface area was significantly correlated with root length, shoot length, root weight, carotenoids, chlorophyll-a and total weight of seedlings. Root length was significantly correlated with carotenoids, leaf surface area, shoot length and root weight. Root weight was significant correlated with chlorophyll-a, number of leaves, shoot length and total weight of seedling. Shoot length was significantly correlated with chlorophyll-a, leaf surface area, number of leaves, root length, root weight and total weight of seedlings.

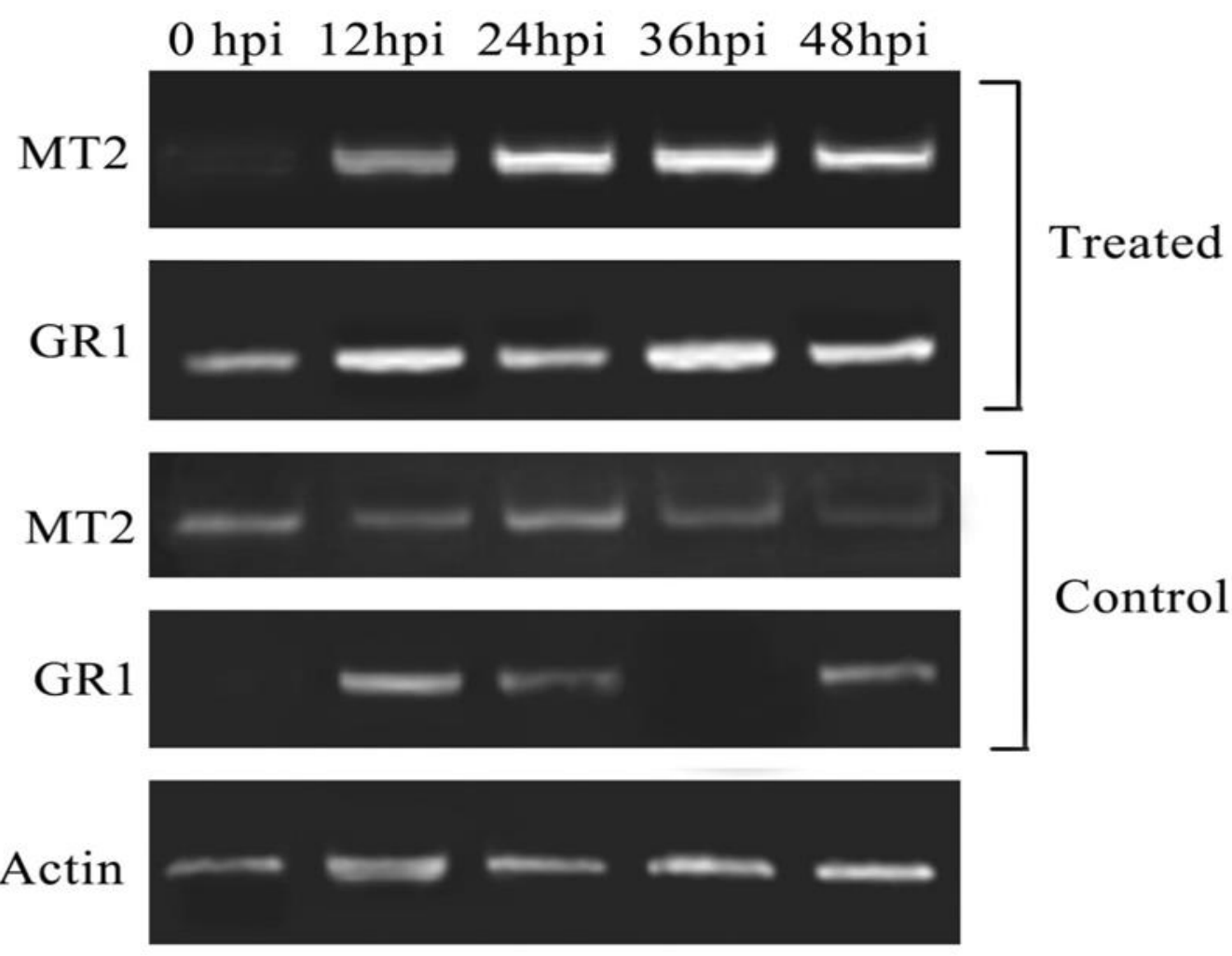

Figure 7 Effect of Bacillus megaterium zm7 strain on expression of stress-related genes transcripts. * MT represents the mettalothionein gene while $* *$ GT represents the glutothion gene.Beta-actin was used as internal control.

Table 2 Correlation matrix for various morphological and biochemical traits of tomato plants grown in salt stress environment, 15 days post PGPR application.

\begin{tabular}{|l|l|l|l|l|l|l|l|l|l|l|}
\hline Traits & \multicolumn{1}{|c|}{ Ant } & \multicolumn{1}{c|}{ Car } & \multicolumn{1}{c|}{ Cha } & Chb & Lsa & Nl & Rl & Rw & Sl & Sw \\
\hline Car & $0.3753^{*}$ & & & & & & & & & \\
\hline Cha & $0.5139^{*}$ & -0.1227 & & & & & & & & \\
\hline Chb & $-0.3674^{*}$ & $0.5477^{*}$ & $-0.3717^{*}$ & & & & & & & \\
\hline Lsa & $0.4298^{*}$ & -0.2221 & -0.276 & $0.5337^{*}$ & & & & & & \\
\hline Nl & $-0.3921^{*}$ & $-0.5269^{*}$ & $0.7098^{*}$ & -0.0283 & 0.2255 & & & & & \\
\hline Rl & 0.0661 & $0.477^{*}$ & 0.0094 & -0.3041 & $0.3444^{*}$ & $-0.4803^{*}$ & & & & \\
\hline Rw & 0.3288 & -0.273 & $0.8541^{*}$ & -0.2968 & -0.281 & -0.361 & $-0.4183^{*}$ & & & \\
\hline Sl & 0.3208 & $0.3984^{*}$ & -0.0878 & 0.2079 & -0.2002 & 0.113 & -0.1436 & -0.2969 & & \\
\hline Sw & $0.6300^{*}$ & $0.4037^{*}$ & $0.8942^{*}$ & $0.4926^{*}$ & -0.014 & $-0.4178^{*}$ & -0.2509 & $0.9300^{*}$ & -0.1563 & \\
\hline Tw & $0.5177^{*}$ & -0.0557 & -0.3308 & -0.2454 & $0.9323^{*}$ & 0.1018 & $0.3308^{*}$ & $-0.3873^{*}$ & -0.0415 & -0.1094 \\
\hline
\end{tabular}

Ant: Anthocyanin; Car: Carotenoids; Cha: Chlorophyll- a; Chb: Chlorophyll-b; Lsa: Leaf surface area; Nl: No of leaves; Rl: Root length; Rw: Root weight; Sl: Shoot length; Sw: Shoot weight; Tw: Total weight 
Table 3 Correlation matrix for various morphological and biochemical traits of tomato plants grown in salt stress environment, 30 days post PGPR application.

\begin{tabular}{|l|l|l|l|l|l|l|l|l|l|l|}
\hline Traits & \multicolumn{1}{|c|}{ Ant } & \multicolumn{1}{c|}{ Car } & Cha & Chb & Lsa & Nl & Rl & Rw & Sl & Sw \\
\hline Car & $0.5184^{*}$ & & & & & & & & & \\
\hline Cha & -0.2305 & -0.0025 & & & & & & & & \\
\hline Chb & $0.8228^{*}$ & $0.6878^{*}$ & 0.1662 & & & & & & & \\
\hline Lsa & 0.2049 & $0.5953^{*}$ & $0.5407^{*}$ & -0.3463 & & & & & & \\
\hline Nl & 0.0872 & -0.0307 & -0.1719 & -0.1673 & $0.5496^{*}$ & & & & & \\
\hline Rl & -0.0084 & $0.5467^{*}$ & $-0.4033^{*}$ & 0.0256 & $0.8465^{*}$ & 0.1997 & & & & \\
\hline Rw & $-0.4002^{*}$ & $-0.3769^{*}$ & $0.7651^{*}$ & $0.465^{*}$ & $0.8914^{*}$ & $0.6354^{*}$ & $0.5968^{*}$ & & & \\
\hline Sl & 0.1322 & 0.2814 & $0.7685^{*}$ & -0.0974 & $0.9033^{*}$ & $0.5101^{*}$ & $0.8237^{*}$ & $0.901^{*}$ & & \\
\hline Sw & $0.8957^{*}$ & 0.2932 & 0.1271 & $0.6444^{*}$ & -0.2166 & -0.0867 & -0.3431 & 0.0215 & -0.2794 & \\
\hline Tw & $0.4819^{*}$ & -0.2283 & $0.9421^{*}$ & $0.397^{*}$ & $0.6842^{*}$ & $-0.3261^{*}$ & $-0.4817^{*}$ & $0.8959^{*}$ & $0.8312^{*}$ & -0.095 \\
\hline
\end{tabular}

Ant: Anthocyanin; Car: Carotenoids; Cha: Chlorophyll- a; Chb: Chlorophyll-b; Lsa: Leaf surface area; Nl: No of leaves; Rl: Root length; Rw: Root weight; Sl: Shoot length; Sw: Shoot weight; Tw: Total weight

\section{Discussion}

A major environmental stress, salinity, adversely affects the plant growth and development. Growth reduction is caused by two factors; initial is the osmotic effect while second phase include increase of salt toxicity levels in plant leaves. Only the plants tolerant to salt stress can survive this second phase and prevent accumulation of the salts in the leaves to a toxic level (Lauchli and Grattan, 2007). Exposure of plants to saline environment cause reduction in certain morphological and physiological traits that decrease the overall plant growth (Aranda et al., 2001). This is because of the fact that with salt stress, water uptake efficiency of the plant is decreased (Munns and Tester, 2008) which results in retarded growth of the plant. Salt tolerance of any plant can be measured by increase or decrease in the yield of subjected plant (Maggio et al., 2007) and it is reported that the vegetative growth of the plant is more sensitive to salt stress as compared to the reproductive growth (Lauchli and Grattan, 2007). In the present study, overall growth of the control, untreated tomato plants that were exposed to salt treatment showed retarded growth in perspective of morphological parameters measured. Specifically, they showed decreased growth in shoot length, root length, mass of the shoot, total weight, weight of the root, leaf surface area and number of leaves. It is believed that cells respond quickly to salt stress as they dehydrate and shrink initially. This condition is overcome by the cells and regains their length after several hours but despite their recovery, cell elongation and cell division to some extent, is reduced that leads to retarded growth of the leaf and root. Afterward accumulation of salt in leaves to toxic levels led to delayed leaf appearance and increase in leaf size while shoot development is the later symptom of salt injury to the plant (Munns, 2002a). While high amount of accumulated salts in soil hinder the roots potential to drag out the water (Hasegawa et al., 2000; Munns et al., 2008). This scenario generates visible and clear differences in the overall growth of salt-stressed plants and control, non-stressed plants. The similar findings were met in the current study where PGPR treated plants showed green leaves as compared to untreated tomato plants that have yellowish leaves during salt treatment. Our findings are in parallel to Grava et al.
(2004) where restrained salinity affects the size of tomato fruit because of restricted water transport. Plant growth promoting rhizobacteria (PGPR) refers to a varied group of colonizing bacteria which is found in rhizosoheric soil. They stimulate plant growth via certain direct and indirect promotions (Vessey, 2003; Banchio et al., 2008). Specifically, PGPR helps the plant in uptake of nutrients; solubilization of nutrients as phosphorous, nitrogen, potassium etc via inoculation (phytohormones); production of plant growth regulators; acting as biocontrol agents by protecting plant from phytopathogens via squirting siderophores; bioremidiating the polluted soils by sequestering toxic heavy metal species and degrading xenobiotic compounds (like pesticides) and finally through improving soil structure (Szczech et al., 2004; Braud et al., 2009; Hayat et al., 2010; Rajkumar et al., 2010; Ahemad and Malik, 2011; Ahemad, 2012; Mohamed et al., 2015; Shan et al., 2015; Singh et al., 2013; Zafar et al., 2015; Zameer et al., 2015b).

Plants respond to salt stress by cellular, biochemical, tissue and whole plant level. Certain biochemical pathways that expedite the withholding capacity of water determine the tolerance of plants to salinity (Parida and Das, 2005). The resulting biochemical toxicity seriously affects assimilation and nutrient uptake (Hasegawa et al., 2000; Munns et al., 2008). In current findings, when tomato plants were irrigated with saline water, overall growth of the plants was affected regarding decline in physical traits (fresh weight, dry weight, leaf number etc). Overall, chlorophyll content, carotenoid and anthocyanin content of the PGPR-treated salt-stressed plants was increased as compared to the untreated, salt stressed tomato plants. Bacteria growing in soil acquire iron by the secretion of low-molecular mass iron chelators referred to as siderophores. In both Gram-negative and Grampositive rhizobacteria, iron $\left(\mathrm{Fe}^{3+}\right)$ in $\mathrm{Fe}^{3+}$-siderophore complex on bacterial membrane is reduced to make iron available to both plant and bacteria itself (Schmidt, 1999; Indiragandhi et al., 2008; Rajkumar et al., 2010). Iron functions as a chelating agent in chlorophyll and availability of iron to plants by PGPR enhance their photosynthetic activity and the growth overall. PGPR 
proved to enhance solubilization and uptake of nutrients in direct promotions thus to modulate plant growth and development (Figueiredo et al., 2010). While indirectly, PGPR are reported to promot eradication of deleterious effects of organism and in a study, provoke induced systematic tolerance towards salt (Van, 2007; Yang et al., 2008).

In similar studies, Ahemad and Khan (2012e), Ahemad and Khan (2011k) and Ahemad and Khan (2010d) used Pseudomonas sp. PS in Greengram (Vigna radiata) plant and found significant increase in plant dry weight, nodule numbers, total chlorophyll content, leghaemoglobin, root nitrogen, shoot nitrogen, root phosphorus, shoot phosphorus, seed yield and seed protein. In a related study by Ma et al. (2011b) who used Psychrobacter sp. SRS8 for Ricinus communis, Helianthus annuus and obtained stimulated plant growth and $\mathrm{Ni}$ accumulation in both plant species with increased plant biomass, chlorophyll, and protein content. Wani and Khan (2010) used Bacillus species PSB10 as PGPR for chickpea (Cicer arietinum) and found significant improvement in growth, nodulation, chlorophyll, leghaemoglobin, seed yield and grain protein; reduced the uptake of chromium in roots, shoots and grains. The significant correlation among the traits found in the present study suggested that the application of PGPR strains caused an important effect on the morphological and biochemical traits to withstand the tomato plants under salt stress conditions (Ali et al., 2013; Ali et al., 2014a,b; Fawad et al., 2015; Dar et al., 2014; Tariq et al., 2014).

\section{Conclusion}

The Bacillus megaterium strain $\mathrm{Zm} 7$ has potential to improve plant growth by uplifting various morphological and biochemical parameters in salt-stressed environment. If this applied as PGPR, it has the potential to induce salt tolerance to a significant extent in any particular plant.

\section{References}

Adesemoye AO, Kloepper JW. .2009. Plant-microbes interactions in enhanced fertilizer-use efficiency. Appl Microbiol Biotechnol $85: 1-12$.

Ahemad M. .2012. Implications of bacterial resistance against heavy metals in bioremediation: a review. IIOABJ 3: 39-46.

Ahemad M, Malik A. 2011. Bioaccumulation of heavy metals by zinc resistant bacteria isolated from agricultural soils irrigated with wastewater. Bacteriol J 2:12-21.

Ahemad M, Khan MS. 2012e. Alleviation of fungicide-induced phytotoxicity in greengram [Vigna radiata (L.) Wilczek] using fungicide-tolerant and plant growth promoting Pseudomonas strain. Saudi J Biol Sci 19: 451-459.

Ahemad M, Khan MS. 2011k. Pseudomonas aeruginosa strain PS1 enhances growth parameters of greengram [Vigna radiata $(\mathrm{L}$. Wilczek] in insecticide-stressed soils. J Pest Sci 84: 123-131.

Ahemad M, Khan MS. 2011d. Effect of pesticides on plant growth promoting traits of greengram-symbiont, Brady rhizobium $\mathrm{sp}$ Strain MRM6. Bull Environ Contam Toxicol 86: 384-388.

Ali Q, Ahsan M, Ali F, Aslam M, Khan NH, Munzoor M, Mustafa HSB, Muhammad S. 2013. Heritability, heterosis and heterobeltiosis studies for morphological traits of maize (Zea mays L.) seedlings. Adv. life sci., 1(1): 52-63.
Ali Q, Ali A, Tariq M, Sarwar B, Ahmad M, Awaan MF, Husnain T. 2014a. Gene Action for Various Grain and Fodder Quality Traits in Zea Mays. Journal of Food and Nutrition Research, 2(10): 704-717.

Ali Q, Ali A, Ahsan M, Ali S, Khan NH, Muhammad S, Abbas HG, Nasir IA, Husnain T. 2014b. Line $\times$ Tester analysis for morphophysiological traits of Zea mays L. seedlings. Adv. life sci., 1(4): 242-253.

Aranda RR, Soria T, Cuartero J. 2001. Tomato plant-water uptake and uptake and plant-water relationships under saline growth conditions. Plant Sci 160(2): 265-272.

Banchio E, Bogino PC, Zygadlo J, Giordano W. 2008. Plant growth promoting rhizobacteria improve growth and essential oil yield in Origanummajorana L. Biochem Syst Ecol 36(10):766-771.

Bhattacharyya PN, Jha DK. 2012. Plant growth-promoting rhizobacteria (PGPR): emergence in agriculture. World J Microbiol Biotechnol 28: 1327-1350.

Borsani O, Valpuesta V, Botella MA. 2003. Developing salt tolerant plants in a new century: A molecular biology approach. Plant Cell Tiss Org 73(2): 101-115.

Braud A, Jezequel K, Bazot S, Lebeau T. 2009. Enhanced phytoextraction of an agricultural $\mathrm{Cr}-, \mathrm{Hg}$ - and $\mathrm{Pb}$-contaminated soil by bio-augmentation with siderophore producing bacteria. Chemosphere 74: 280-286.

Cuartero J, Boların MC, Asıns MJ, Moreno V. 2006. Increasing salt tolerance in tomato. J Exp Bot 57(5): 1045-1058.

Dar AI, Saleem F, Ahmad M, Tariq M, Khan A, Ali A, Husnain T. 2014. Characterization and efficiency assessment of PGPR for enhancement of rice (Oryza sativa L.) yield. Adv Life Sci 2(1): 38-45.

Ezlit YD, Smith RJ, Raine SR. 2010. A review of salinity and sodicity in irrigation. Australia: Cooperative Research Centre for Irrigation Futures. Pp: 1-70.

Fawad A, Naila K, Muhammmad A, Qurban A, Irshad B, Nabeel KN. 2015. Multivariate Analysis of Grain Yield and Its Attributing Traits in Different Maize Hybrids Grown under Heat and Drought Stress Scientifica, vol. 2015, Article ID 563869, 6 pages, doi:10.1155/2015/563869.

Figueiredo MVB, Seldin L, de Araujo FF, Mariano RLR. 2010. Plant growth promoting rhizobacteria: Fundamentals and applications. Microbiol. Monographs, 18: 21-43.

Glick BR, Cheng Z, Czarny J, Cheng Z, Duan J. 2007. Promotion of plant growth by ACC deaminase-producing soil bacteria. Eur J Plant Pathol 119:329-39.

Goupil P, Souguir D, Ferjani E, Faure O, Hitmi A, Ledoigt G. 2009. Expression of stress-related genes in tomato plants exposed to arsenic and chromium in nutrient solution. J Plant Res 166(13): 1446-1452.

Hasegawa PM, Bressan RA, Zhu JK, Bohnert HJ. 2000. Plant cellular and molecular responses to high salinity. Annu Rev Plant Physiol Plant Mol Biol 51: 463-499.

Hayat R, Ali S, Amara U, Khalid R, Ahmed I. 2010. Soil beneficial bacteria and their role in plant growth promotion: a review. Ann Microbiol 60: 579-598.

Indiragandhi P, Anandham R, Madhaiyan M, Sa TM. 2008. Characterization of plant growth-promoting traits of bacteria isolated from larval guts of diamondback moth Plutella xylostella (Lepidoptera: Plutellidae). Curr Microbiol 56: 327333.

Korneli C, David F, Biedendieck R, Jahn D, Wittman C. 2012. Getting the big beast to work-Systems biotechnology of Bacillus megaterium for novel high proteins. J Biotechnol 163(2): 87-96.

Lauchli A, Grattan SR. 2007. Plant growth and development under salinity stress in Advances in Molecular Breeding Toward Drought and Salt Tolerant Crops edited by M.A. Jenks et al. (eds.), 1-32.

Martinez-Beltran J, Manzur CL. 2005. Overview of salinity problems in the world and FAO strategies to address the problem. In: Proceedings of the International Salinity Forum, Riverside, California, April 2005, pp. 311-313. 
Ma Y, Rajkumar M, Vicente JA, Freitas H. 2011b. Inoculation of Ni-resistant plant growth promoting bacterium Psychrobacter sp. strain SRS8 for the improvement of nickel hytoextraction by energy crops. Int J Phytoremediation 13: 126-139.

Maggio A, Raimondi G, Martino A, De Pascale S. 2007. Salt stress response in tomato beyond the salinity tolerance threshold. Environ Exp Bot 59 (3): 276-282.

Mohamed BB, Sarwar MB, Hassan S, Rashid B, Aftab B, Husnain T. 2015. Tolerance of Roselle (Hibiscus Sabdariffa L.) Genotypes to Drought Stress at Vegetative Stage. Advancements in Life Sciences, 2(2): 74-82.

Munns R. 2002a. Comparative physiology of salt and water stress. Plant Cell Environ 25: 239-250.

Munns R. 2005. Genes and salt tolerance: bringing them together. New Phytol 167: 645-663.

Munns R, James RA, Lauchli A. 2006. Approaches to increasing the salt tolerance of wheat and other cereals. J Exp Bot 57: 10251043.

Munns R, Tester M. 2008. Mechanisms of salinity tolerance. Annu Rev Plant Biol 59: 651-681.

Nadeem SM, Zahir ZA, Naveed M, Ashraf M (2010b). Microbial ACC-deaminase: prospects and applications for inducing salt tolerance in plants. Crit Rev Plant Sci 29:360-93.

Nadeem SM, Ahmad M, Zahir ZA, Javaid A, Ashraf M. 2014. The role of mycorrhizae and plant growth promoting rhizobacteria (PGPR) in improving crop productivity under stressful environments. Biotechnol Advan 32: 429-448.

Parida AK, Das AB. 2005. Salt tolerance and salinity effects on plants: a review. Ecotoxicol Environ Saf 60(3): 324-49.

Pitman MG, Lauchli A. 2002. Global impact of salinity and agricultural ecosystems. In: Salinity: Environment - Plants Molecules, A. Lauchli and U. Luttge (Eds.). Kluwer Academic Publishers, Dordrecht, pp. 3-20.

Rajkumar M, Ae N, Prasad MNV, Freitas H. 2010. Potential of siderophore-producing bacteria for improving heavy metal phytoextraction. Trends Biotechnol 28: 142-149.

Schmidt W. 1999. Mechanisms and regulation of reduction-based iron uptake in plants. New Phytol 141: 1-26.

Shan MA, Tahira F, Shafique M, Hussain M, Perveen R, Shahzad M, Iqbal M. 2015. Estimation of Different Biochemical Intensities in Drinking Water from Eastern Region of Lahore City. Adv Life Sci. 2(3): 131-134.
Singh JS. 2013. Plant growth promoting rhizobacteria- potential microbes for sustainable agriculture. Reson 18 (3): 275-281.

Steel RGD, Torrie JH, Dickey DA. 1997. Principles and Procedures of Statistics: A biometrical approach. McGraw Hill Book Co. New York. USA. pp: 400-428.

Szczech M, Dysko J. 2004. The possibility to use selected mixtures of PGPR bacteria in tomato cultivation. Veg Crop Res Bull 68(1): 47-56.

Tariq M, Ali Q, Khan A, Khan GA, Rashid B, Rahi MS, Ali A, Nasir IA, Husnain T. 2014. Yield potential study of Capsicum annuиm L. under the application of PGPR. Adv Life Sci 1(4): 202-207.

Van Loon LC. 2007. Plant responses to plant growth-promoting rhizobacteria. Eur J Plant Pathol 119(3): 243-254.

Vessey JK. 2003. Plant growth promoting rhizobacteria as biofertilizers. Plant Soil 255(2): 571-586.

Wani PA, Khan MS. 2010. Bacillus species enhance growth parameters of chickpea (Cicer arietinum L.) in chromium stressed soils. Food Chem Toxicol 48: 3262-3267.

Yamaguchi T, Blumwald E. 2005. Developing salt-tolerant crop plants: challenges and opportunities. Trends Plant Sci 10:615620 .

Yang J, Kloepper JW, Ryu C. 2008. Rhizosphere bacteria help plants tolerate abiotic stress. Trends Plant Sci 14(1): 1-4.

Zafar SA, Shokat S, Ahmed HGMD, Khan A, Ali MZ, Atif RM. 2015. Assessment of salinity tolerance in rice using seedling based morpho-physiological indices. Adv Life Sci. 2(4): 142149.

Zahir ZA, Munir A, Asghar HN, Shahroona B, Arshad M. 2008. Effectiveness of rhizobacteria containing ACC-deaminase for growth promotion of peas (Pisum sativum) under drought conditions. J Microbiol Biotechnol 18: 958-63.

Zameer M, Tabassum B, Ali Q, Tariq M, Zahid H, Nasir IA, Baqir M. 2015a. Role of PGPR to improve potential growth of tomato under saline condition: An overview. Life Sci J 12(3s): 54-62.

Zameer M, Mahmood S, Mushtaq Z, Tabasum B, Ali Q, et al. .2015 b. Detection of bacterial load in drinking water samples by 16s rRNA ribotyping and RAPD analysis. Adv Life Sci 2(3): $135-141$. 